Composites Part A: Applied Science and Manufacturing

April 2018, Volume 107, Pages 94-104

http://dx.doi.org/10.1016/i.compositesa.2017.12.016

http://archimer.ifremer.fr/doc/00416/52788/

(C) 2018 Elsevier Ltd. All rights reserved

\title{
An experimental study of water diffusion in carbon/epoxy composites under static tensile stress
}

\author{
Humeau Corentin ${ }^{1,{ }^{*}}$, Davies Peter ${ }^{1}$, Jacquemin Frédéric ${ }^{2}$
}

1 IFREMER Centre Bretagne, Marine Structures Laboratory, 29280 Plouzané, France

${ }^{2}$ GeM, Université de Nantes, 58 rue Michel Ange, 44600 Saint-Nazaire, France

* Corresponding author : Corentin Humeau, email address : corentin.humeau@ifremer.fr

peter.davies@ifremer.fr ; frederic.jacquemin@univ-nantes.fr

\begin{abstract}
:
The coupling between tensile stress and water diffusion in composites represents a major issue in many marine applications. Even if these two behaviours are well documented as separate subjects, there are still very few data on fully coupled mechanisms. The aim of this study is to understand what governs the coupled behaviour, by investigating the water diffusion in carbon/epoxy. The coupling is first evaluated on neat resin samples to characterise the matrix behaviour. Then the study focuses on composites with two types of woven fibre orientation: one at $\pm 45^{\circ}$, in order to understand the coupling effects on materials loaded away from the reinforcement direction and another quasi-isotropic to obtain properties along the fibres. For each material the same approach was applied: first, the tensile behaviour, damage development and water diffusion were studied uncoupled. Then, semi-coupled effects were investigated. The final part of the paper combines both behaviours as fully coupled phenomena
\end{abstract}

Keywords : Composite, Moisture diffusion, Static tensile stress, Coupled behaviour 


\section{Context}

The oceans cover more than $70 \%$ of the earth's surface and represent a major source of energy (currents, wind, mineral resources, etc). In recent years this energy potential has induced a constant expansion of the marine industry through key sectors such as marine renewable energies, deep sea mining and boat construction. Nevertheless, the marine environment involves such harsh conditions that materials used in offshore constructions have to be specially chosen. During the last decades it has been shown that thermoset composite materials are well adapted for marine applications, due to their interesting strength/weight ratio, their good properties in fatigue and the low effect of water on their mechanical properties [1]-[3]. Carbon fibres show particularly good characteristics when used as reinforcements, thanks to their excellent strength/weight ratio and good interface properties with thermoset resins. Therefore the material studied here is an epoxy resin reinforced with carbon fibres.

Water uptake in composites and its influence on their mechanical behaviour, treated as uncoupled phenomena, has been widely studied. Water diffusion in polymers and composites has been investigated, first in experimental programmes [4]-[13] which have highlighted characteristic water uptake tendencies depending on parameters such as resin type, fibre orientation, defects in the material and water temperature. The studies [9], [8], [11]-[14] established different diffusion theories corresponding to the phenomena identified experimentally. In the present study the composites are epoxy based and do not contain significant defects, which means that water uptake will most likely show Fickian diffusion.

In terms of tensile behaviour carbon fibre reinforced epoxies show a typically brittle behaviour when they are tested along the fibre direction and could be considered as purely elastic as shown in [15], [16]. In the case of neat resin and composites loaded at an angle to fibres, there will be a first elastic response, until reaching a yield value where plastic deformation becomes significant. This type of behaviour has been studied in [15], [17]-[19].

Both phenomena (water diffusion and mechanical behaviour) have also been studied as semi-coupled effects: considering the influence of one on the other. Theories on pre-stressing and damage effects on water diffusion have been developed either in a thermodynamic way in 
[20], [21], by considering diffusion inside cracks, by changing boundary conditions as Perreux et al. studied in [22]-[25] or by treating the diffusion as two interconnected diffusion mechanisms: one inside the cracks and another in the solid uncracked material as developed in [26], [27]. All these theories predict a water uptake which increases after damage introduction. Experimental work highlights the same trend and various studies [20]-[22], [24] have related theory and experimental data with good correlations.

As shown in [28]-[30], water uptake can promote two degradation types: physical and chemical, which affect the mechanical behaviour of the polymer. The former is created by water molecules located in the polymer network which induce a deformation of the chains and modify the internal strain state (swelling effects). For high water concentration this deformation can result in breakage of the weak bonds between polymer chains (plasticization phenomenon). Chemical degradation is created by a reaction between polymer and water compounds, such as hydrolysis. Both phenomena induce a loss of strength and modulus in aged materials.

Despite significant knowledge on uncoupled and semi-coupled behaviour, there are still very few studies focused on fully coupled behaviour [31], [32]. This is mainly due to the testing difficulties under these conditions.

This rapid literature overview highlights a lack of experimental data and theories for fully coupled behaviour, and the present study aims to investigate the water diffusion and mechanical stress from this angle. Moreover, stresses applied to composites during their life time can be diverse (static, dynamic, tension, shear, compression). In order to establish a baseline in the field of coupled behaviour the first step is the understanding of static behaviour. In order to minimise the number of parameters, only tension and shear loads will be examined here.

\section{Experimental study}

\subsection{Experimental details}

Three types of materials were used: one neat epoxy resin, and two Carbon/Epoxy composite (CFRE - Carbon Fibre Reinforced Epoxy) materials based on the same epoxy in prepreg form, one made with four plies of $+/-45^{\circ}$ woven fibres and one quasi-isotropic CFRE with the following sequence of woven fibres: $\left(0^{\circ} / 90^{\circ},+/-45^{\circ} \mid+/-45^{\circ}, 0^{\circ} / 90^{\circ}\right)$. All materials 
were made by autoclave processing and based on a commercial epoxy resin combined with a polyamine hardener (LY556 and XB3403 from Huntsman). Using these samples the properties of pure resin, and of composites loaded along and at an angle to the fibre directions were determined. The thickness, glass transition temperature ( $\mathrm{Tg}$ ) and resin content of each material type are reported in Table 1. X-ray tomography and optical microscopy were used to check the material microstructure. Figure 1 shows an example, obtained using a LEICA DM ILM microscope and a GE Phoenix V-TOM-X240 tomograph with a resolution of 28 $\mathrm{mm}^{3} /$ voxcel.

To investigate the coupling between water diffusion and tensile static stress, three types of tests were used: water diffusion measurements, quasi-static tensile tests, and water diffusion under static tension stress (coupled tests).

Water diffusion properties were studied on all the three materials: neat resin and both types of composites. Considering the glass transition temperature $(\mathrm{Tg})$ to be around $120^{\circ} \mathrm{C}$ (cf. Table 1) for all dry specimens, the water uptake was studied at $60^{\circ} \mathrm{C}$ here in order to accelerate the diffusion phenomena. Diffusion specimens were $50 \times 50 \mathrm{~mm}$ square plates, dried until weight stabilisation before ageing. The samples were then immersed in natural sea water, and weighed regularly to identify diffusion laws.

Mechanical behaviour considered in this work is for quasi-static tension, which is described by standardised test methods: ASTM D3039 for composites and ASTM D638 for the polymer resin. Moreover, damage must be characterised. Various techniques exist to quantify damage in composites: the modulus change criterion, $\mathrm{D}$, has been used in various studies [22], [23], [33], while acoustic emission signal analysis has been investigated in [34], [35], and X-ray analysis was employed in [36]. Several other authors have shown interesting results with a physical damage characterisation by direct crack density identification [25], [26], [37].

For this study we chose to characterise damage with the latter technique, direct crack surface density measurements, in order to have a simple method (compared to acoustic emission) which could characterise damage in quasi-isotropic composites (contrary to the modulus change criterion, D). To identify crack density during tensile tests one side of the samples was painted white to differentiate surface of cracks and undamaged material, as shown on Figure 2. The cracked area was then analysed by image subtraction compared with the reference (the image of the sample before loading) using a Matlab ${ }^{\mathrm{TM}}$ routine. A threshold is applied on this subtraction; the threshold value is established by the operator in order to highlight the crack 
and erase the parasitic defects, based on the image of the first crack appearance. An area analysis was then performed, to obtain the surface proportion of black regions (cracks).

During ageing the Tg was determined after different exposure times, by DMA (Dynamic Mechanical Analysis) using the loss of modulus with test temperature to identify changes. The tests were performed in tension on a Metravib ${ }^{\mathrm{TM}}$ DMA in an oven at ambient humidity, at $2{ }^{\circ} \mathrm{C} / \mathrm{min}$ over the temperature range from $20^{\circ} \mathrm{C}$ to $150^{\circ} \mathrm{C}$, and at with a frequency of $1 \mathrm{~Hz}$ and cycled under a dynamic strain amplitude of $5.10^{-3}$.

Coupled tests involving water diffusion and tensile stress were specially developed in this study. A test bench has been developed (shown in Figure 3) on which samples can be immersed in water heated at $60^{\circ} \mathrm{C}\left(+/-0.5^{\circ} \mathrm{C}\right)$. Here we use tap water constantly renewed, in order to avoid both oxidation of the container and chemical modification of the water. Specimens were loaded under a static tension by lever arms and weights. During testing, water uptake and dimensional variations were recorded periodically.

\subsection{Uncoupled behaviours}

The first step of the study was to determine the uncoupled properties. First water uptake will be presented, then the tensile behaviour of composites and resin.

\subsubsection{Water uptake}

Water uptake was measured on the three types of material (resin, $+/-45^{\circ}$ and quasiisotropic). The water uptake in the resin is taken as a reference. If water diffuses only in the matrix of the composite, then water uptake values in composites can be defined from the initial weight of resin. Figure 4 shows weight gains for the neat resin and the composites' matrix. The diffusion rate in the neat resin is faster than in composites. This phenomenon has been studied in [12], it is explained by the presence of fibres which represent obstacles to water diffusion in their transverse direction. Moreover, the slight differences between maximal moisture uptakes can be induced, in the resin case, by a low number of data points during the saturation stage, not sufficient for identification.

Experimental data indicate diffusion ruled by a Fickian tendency as for many epoxy resins exposed to water below their glass transition temperature. The geometry of the samples allows us to consider a unidirectional diffusion in the specimen thickness direction. To identify the parameters of Fick's law in this case we use the least square method to find the 
best parameters (diffusion coefficient, $\mathrm{D}$ and maximal water uptake, $\mathrm{M}_{\infty}$ ) in order to fit the experimental values all along the curve. The identification consists of four steps:

- Creating an artificial Fick function by choosing arbitrary parameters (of the order of magnitude of the real ones).

- Generating randomly different values of the parameters around the chosen one.

- Comparing the experimental values with theories in each point and for every parameter by the least square method.

- The parameters minimising the square difference between experiment and theory are chosen as the parameters for the first step of the next iteration.

The routine is repeated until the square difference between theory and experimental data is lower than a certain value or after a given number of iterations.

The functions identified are shown in Figure 4, the parameters of Fick's laws at $60^{\circ} \mathrm{C}$ are reported in Figure 13 in section 2.3.2 below. As noted in [12] the presence of the fibres slows the diffusion in the transverse direction of the composite.

The diffusion in water at $60^{\circ} \mathrm{C}$ accelerates the ageing phenomenon. Water uptake tests have also been performed at $25^{\circ} \mathrm{C}$ and show an estimated time to saturation multiplied by fourteen compared with immersion at $60^{\circ} \mathrm{C}$.

\subsubsection{Mechanical behaviour}

Reference tests were performed on samples dried until weight stabilisation at $0 \% \mathrm{RH}$ and $60^{\circ} \mathrm{C}$.

Tensile testing in the case of polymer based material present some specific characteristics: first a linear behaviour corresponding to the material modulus, then an ultimate stress and strain, and in some cases a yield stress and strain. All the measured mechanical properties are summarised in Table 2 for all three materials.

During tensile tests, the damage is also characterised using the crack density, represented in Figure 7 and Figure 9. This type of analysis provides the following damage properties (reported in Table 2):

- The strain and stress damage thresholds, which were defined as the stress and strain corresponding to a damage density equal to $5 \%$ of the crack areal density at failure.

- The crack density growth rate, characterised by the asymptote of the second part of the crack density curves. 
- The ultimate crack density.

\subsection{Partly coupled behaviours}

Knowing both behaviours separately, the next step is to investigate the influence of one phenomenon on the other as semi-coupled behaviours. This step avoids combined phenomena which appear during fully coupled testing.

\subsubsection{Water uptake effects on mechanical behaviour}

Published studies show an influence of water diffusion on polymer and composite tensile behaviour by plasticization or chemical degradation. To get a full understanding of this phenomenon the tensile mechanical behaviour was tested after different ageing durations in seawater at $60^{\circ} \mathrm{C}$. The transition temperature $(\mathrm{Tg})$ is also controlled during water diffusion to make sure the gap with the testing temperature does not become critical in terms of mechanical performance. The Tg value obtained in this case is a global quantity. Indeed, the DMA testing is made on samples in a transient stage of the diffusion, which induces a gradient of $\mathrm{Tg}$ through the material thickness. The reason behind this choice is that tests on coupled effects need a good knowledge of the material properties in the transient stage of the diffusion and not only in a stabilised state.

\section{Neat resin}

The literature review highlights two types of property loss by ageing: the water molecules affect the mechanical behaviour of the polymer either in a physical (swelling, plasticization) or chemical way. To identify both types of phenomenon we have to perform tests in the transient stage of the diffusion for physical effects and in the stable state to examine for eventual chemical reactions.

It is assumed that the chemical reactions (hydrolysis and oxidation) can be neglected in water at $60^{\circ} \mathrm{C}$ in the type of amine cured epoxy resin used here $[38,39]$. Therefore, tests were performed in the transient stage of the diffusion in order to characterise the water effect on the materials. These tests were conducted after three different ageing times corresponding to $\sqrt{t}_{\mathrm{t}} \mathrm{e}$ values of 5.5, 10 and $15 \sqrt{ } \mathrm{h} / \mathrm{mm}$ respectively named "Aged 1-X", "Aged 2-X", and "Aged 3$\mathrm{X}$ " (with $\mathrm{X}$ the sample number or average; $\mathrm{t}$ the time and e the sample thickness).

During ageing the tensile modulus of neat resin is not affected by water uptake, nevertheless in the transient stage (ageing time " 0 ", "1" and " 2 ") failure occurs sooner than in 
the unaged case, ultimate strain and stress decrease with exposure time as shown in Figure 5 [left]. Tests performed on aged samples show identical failures in the cases "2" and "3", therefore the degradation stabilises close to the saturation level:.

Considering that we study mechanical properties, the most relevant transition temperature value is obtained by considering the loss of storage modulus, which best represents the loss of mechanical properties. Water uptake creates plasticization of the polymer, increasing chain mobility and decreasing the $\mathrm{Tg}$ value as shown in Figure 5 [right]. At the saturation stage the $\mathrm{Tg}$ value stabilises at $66^{\circ} \mathrm{C}$. Moreover, DMA measurements highlight two Tg peaks. This phenomenon could be explained by water desorption when the sample is heated during DMA tests, which induces an increase of $\mathrm{Tg}$ and results in a second glass transition corresponding to the dry state.

\section{+/-45 woven composites}

For $+/-45^{\circ}$ woven composites mechanical properties and glass transition temperatures were studied on both unaged and fully saturated specimens.

Mechanical behaviour of $+/-45^{\circ}$ composites is highly dependent on neat resin behaviour. The water diffusion has the same effects on the composite as on the resin: ultimate stress and strain are lower after ageing due to plasticization of resin, as shown in Figure 6. Nevertheless there is an additional effect for $\pm 45^{\circ}$ composites: the threshold stress is significantly decreased after ageing.

As for conventional mechanical properties, damage quantities are degraded by water uptake. Aged composites show a lower strain/ stress threshold value and the speed of damage development increases, Figure 7.

In saturated composites the strain threshold value is reduced by a factor of more than two (from $4.5 \%$ to $1.5 \%$ ), and stress threshold drops from $150 \mathrm{MPa}$ to $80 \mathrm{MPa}$.

The damage growth rate increases with ageing due to the lower properties of the resin which cracks at lower stress and strain.

Ultimate crack densities increase with ageing. It is known that diffusion affects the polymer properties while carbon fibres do not take up water. In aged samples, the fibres failure will occur at the same stress and strain as in the unaged case whereas the matrix will crack at a lower stress. Combining both phenomena results in an ultimate crack density ratio which is higher in the aged composite (from $20 \%$ to $35 \%$ on average).

All these results are summarised in Table 2. 


\section{Quasi isotropic woven composites}

Unlike $+/-45^{\circ}$ woven, quasi isotropic (Q-iso) composites are less affected by resin property changes as shown in Figure 8, due to the presence of fibres (unaffected by ageing) oriented in the direction of loading. For other kinds of tests involving loading of the interface resin and reinforcement (like inter-laminar shear strength test), there would have been a larger difference between aged and unaged samples.

Damage characterization tests, reported in Figure 9, confirm that threshold values are unaffected by ageing. The cracking threshold depends on fibre properties oriented along the loading direction.

In terms of the damage growth rate it is harder to identify a clear trend since the crack density curves do not show a clear final asymptote, this results in values with high variability.

Damage development rate reaches up to $80 \%_{\text {cracking }} / \%_{\text {strain }}$ which results in large differences in terms of ultimate crack density for a minor variation in ultimate strain as the standard deviation shows (between 30 and 45\%).

\subsubsection{Water diffusion in pre-stressed materials}

Pre-stressing polymer and composite materials can introduce damage into the material, which changes the material microstructure and therefore can affect the subsequent water diffusion into the polymer. The next section investigates this effect when the samples are immersed in seawater at $60^{\circ} \mathrm{C}$.

\section{Neat resin}

Load-unload cycles during quasi-static tensile tests on neat resin revealed no cracks nor permanent deformation or modulus change. For the study of pre-stress effects on water diffusion, three pre-stress levels were chosen; these correspond to stress values in the linear part of the tensile curve (30MPa), the non-linear region (70MPa) and close to failure (80MPa).

Water diffusion measurements on specimens immersed after pre-stressing then unloading are reported in Figure 10 and show no influence of the pre-loading on the water diffusion in the resin. Therefore, the diffusion law used for resin pre-stressed or unstressed will be identical as shown in Figure 10.

\section{$+/-45^{\circ}$ woven composites}


Contrary to the resin, tensile tests on $+/-45^{\circ}$ composites introduce cracks into the polymer matrix. In the case of this kind of damage previous work such as [23] and [24] has shown that damage in the resin increases both the water diffusion coefficient and maximal water uptake in the composite.

Samples were pre-tensioned to three different stresses: 60, 130 and $160 \mathrm{MPa}$ respectively corresponding to 33,75 and $90 \%$ of the break stress (unaged at $25^{\circ} \mathrm{C}$ ).

The identification of diffusion parameters highlights a dependence of diffusion coefficient on the crack density and maximal water content on stress level (Figure 13). Water uptake in $\pm 45^{\circ}$ specimens shows the same linear increase with the pre-stress level (see Figure 11 and Figure 13). Moreover if we analyse in details the diffusion coefficient variations with damage ratio (Figure 13), the increase of the diffusion kinetics corresponds to the beginning of the matrix cracking.

\section{Quasi-isotropic woven composites}

In the case of quasi-isotropic composite water uptake curves (Figure 12), there is a slight increase in diffusion coefficient with the increase in damage and no effect on the final moisture content in the saturated materials.

The fibres aligned with the tension direction favour a purely elastic behaviour. There is a perfect recovery of the material after testing with no permanent deformation. Considering this particularity and that the cracks are the source of water uptake modification, this explains why the pre-stressing does not modify significantly the water uptake in the quasi-isotropic composite.

These results are summarised in Figure 13 as a function of the pre-stressing levels and compared with $+/-45^{\circ}$ composites.

The semi-coupled influence of pre-stressing on water uptake is highly dependant on the fibre orientation with respect to the loading direction. Indeed, for quasi-isotropic composites the pre-stressing has a limited effect on water uptake whereas $+/-45^{\circ}$ materials are highly affected by pre-stressing.

\subsection{Coupled behaviour}

In this section results from tests on composites under combined tensile stress and tap water exposure (at $60^{\circ} \mathrm{C}$ ) will be presented. For each material one set of specimen was immersed without mechanical stress in the same water tank as the other stressed specimens, in 
order to identify the reference diffusion. The diffusion laws identified from these reference samples are represented by continuous lines on Figure 14 [left] and Figure 15. The difference in water activity compared with the previous cases (immersion in seawater) is not believed to be critical since for each case we compare the difference in weight gain with the values for appropriate reference specimens, aged in either seawater or tap water.

\section{$+/-45^{\circ}$ woven composites}

For $+/-45^{\circ}$ composites, four different stresses have been studied: $30,60,110$ and $130 \mathrm{MPa}$ representing respectively 16, 33, 60 and $71 \%$ of the ultimate break stress (for samples unaged tested at $\left.25^{\circ} \mathrm{C}\right)$.

From this experiment three different water uptake behaviours can be highlighted. The time to failure (represented by crossed symbols in Figure 14) is highly dependent on the loading. To get a clearer representation of the diffusion variation with the applied stress Figure 14 shows the water uptake difference between stressed samples and the reference diffusion.

The water uptake of composites stressed above $110 \mathrm{MPa}$ is modified from the start of immersion, while lower stress levels do not affect the diffusion behaviour initially. This difference depends on how close the stress levels are to the cracking threshold (shown in Figure 7), the cracking induces an additional water uptake which accelerates the damage and failure occurs after short immersion times.

A second diffusion behaviour can be identified for specimens stressed above the aged threshold value and below the unaged threshold value. In the first case, water diffusion stay relatively close to the reference during a first stage and starts to deviates after a certain time as Figure 14 shows for samples stressed below 60MPa. Samples stressed below the cracking threshold of aged composites (30MPa) show a constant water uptake difference which remains low (30\%) compared to other coupled cases.

\section{Quasi-isotropic woven composites}

Unlike for $+/-45^{\circ}$ composites, cracking in quasi-isotropic materials is not affected by ageing. Samples were tested at two stress levels: 280 and 450MPa (50 and 80\% of the unaged breaking stress), corresponding respectively to a stress above and below the threshold value. The diffusion curves are shown in Figure 15.

For specimens stressed above the first crack appearance, water uptake increases significantly, compared to the reference. The failure occurs before the stabilisation of the 
water uptake and therefore we cannot clearly identify a diffusion coefficient. The high maximal moisture content highlights the importance of additional water in the composite.

Samples stressed below the damage limit follow the reference diffusion during a first part and start to deviate before the saturation level. Since semi-coupled behaviour does not predict this kind of behaviour, this phenomenon is the results of combined effects of mechanical stress and water diffusion. A possible reason for this deviation could be the modification of the resin mechanical properties by ageing which induces early damage at the interface between fibres and matrix and modifies the water uptake.

\section{Discussion}

\subsection{Damage characterisation}

The crack density parameter used here is an indicator of the amount of damage in a composite stressed under a defined loading. Nevertheless it does not provide any information on the orientation, shape and number of cracks. To characterise the damage more precisely a two step method was applied: first, different typical stages of damage were identified from the images recorded during crack density analysis; next, new samples were stressed under loadings corresponding to these different stages of damage and examined by X-Ray tomography analysis.

\subsubsection{D damage characterisation}

Images from crack analysis can provide information on the type of damage involved during a tensile test. The typical stages we can identify with a 2D study are: inter-ply cracking, intra-ply cracking, and crack coalescence For each test, images were manually analysed in order to identify the different stages of damage, shown in Figure 16 for $+/-45^{\circ}$ composites.

For tests on quasi isotropic composites the limits between the different stages of damage are less distinct. The woven construction represents a barrier to the intra-ply crack propagation, whereas the inter-ply propagation does not have any obstacle. For this reason, when a crack appears the preferential direction of propagation is delamination.

These results have parallels with the influence of loading on the diffusion coefficient. Figure 13 shows a diffusion coefficient strongly affected by the appearance of the first cracks 
(intra-ply cracks) and less affected by the subsequent crack propagation (intra-ply cracks and coalescence).

\subsubsection{D damage characterisation}

The 2D study does not provide information on the crack shape, the cracks are considered to extend across the specimen width, and there is no distinction between intra-ply cracks and delamination damage. X-ray tomography analysis can provide this additional information. A study was performed on specimens which had been pre-stressed to loads corresponding to each stage of the damage identified previously by $2 \mathrm{D}$ characterisation.

The $\pm 45^{\circ}$ composites show high crack density after unloading, even for a pre-stress of $60 \mathrm{MPa}$. First, the crack density estimated by analysing damage on the sample edge shows limitations: crack density by surface analysis is equivalent to zero while volume investigation shows damage. Second, cracks introduced by pre-stressing the sample are not entirely closed after unloading (Figure 17). This explains the significant differences in water diffusion between specimens pre-stressed at different levels.

In the case of quasi-isotropic samples, there is no sign of cracks (Figure 17), which is surprising as at this stress level cracks could be detected visually on the specimen edges. It thus appears that cracks in this composite close up completely when the load is removed, and this explains why there is not a larger effect of pre-stressing on water absorption during the semi-coupled sequences. Nevertheless, during fully coupled tests the cracks will be maintained open (shown in Figure 2) and therefore, coupling effects will be significant.

\subsection{Coupling representation}

Results from the coupled study highlight a dependence of water diffusion on the applied stress. To show this coupling between mechanical behaviour and ageing more clearly we have introduced a new representation.

A convenient way to translate the coupled effects of water diffusion and mechanical behaviour is by evaluating the water uptake difference between stressed and unstressed materials. Then, this parameter is represented as a function of $V_{\mathrm{t}} / \mathrm{e}$ in the case of diffusion after and during static loading in order to enhance the impact of the simultaneous effects of water and stress. This representation is shown in Figure 18 for quasi-isotropic (right) and $\pm 45^{\circ}$ composites (left). 
In the case of $\pm 45^{\circ}$ reinforcements, stressed and pre-stressed samples share the same first stage characterised by a water uptake increased, the duration of this phase depends on the prestress level. It translates the presence of water included in cracks created by tensile stress, and could model by capillary diffusion inside the damages, present in pre-stressed and stressed materials.

The second phase is characterised by a decrease of the water uptake difference in pre-stressed samples while water diffusion starts to accelerate in specimens stressed above the damage threshold stress $(60 \mathrm{MPa})$. This acceleration generated by coupled effects of water and static loadings. On one hand, the cracks induce a lower loaded surface which results in a stress increase and therefore in an acceleration of the damage propagation. On the other hand, the water included in the defects can propagate the damage (especially in case of loading/unloading cycles). These two phenomena combine into a self-accelerated degradation mechanism, as shown in Figure 18 [left].

In the case of quasi-isotropic composites, the initial and second stage still present for prestressed and stressed materials.

Nevertheless, the failure does not occur at the end of the second phase, but the water uptake difference stabilises on a given value ( $150 \%$ in the case of samples stressed under $430 \mathrm{MPa}$ ). The additional water uptake is induced by cracks, and then its stabilisation translates a constant damage density. In quasi-isotropic samples, fibres oriented in the loading direction can support the stress applied on the sample and therefore stop the crack propagation. In this case, the water uptake should be constant from the beginning to the end (constant crack density). Nevertheless the second stage highlights an increase of water uptake difference which can only be explained by damage induced by the property variation of the resin due to water uptake.

Finally the diffusion behaviour of quasi-isotropic and $\pm 45^{\circ}$ composites pre-stressed and stressed highlight an important influence of the coupling on the additional water uptake: $25 \%$ of the reference in the case of pre-stressed materials and $150 \%$ for samples stressed in water.

\subsection{Size effects}

During fully coupled tests two phenomena can induce water uptake modification: either the damage created by aging, or a creep mechanisms due to time under load. To identify the critical phenomenon thinner samples, with the same $\pm 45^{\circ}$ stacking sequence, were tested under coupled conditions. Thus, if ageing is the predominant mechanism tests performed on a 
thin and thick specimens equally stressed would cause a weight increase at the same value of $V_{\mathrm{t}} / \mathrm{e}$. On the contrary, if the creep mechanisms are predominant, both specimen weights (thin and thick) will increase at the same time under load (i.e. a longer value of $\sqrt{t}_{\mathrm{t}} / \mathrm{e}$ for a thinner specimen). To investigate this, $1 \mathrm{~mm}$ thick samples were tested under a stress of $60 \mathrm{MPa}$ and weight gains were compared with results from standard $2.2 \mathrm{~mm}$ thick specimens, Figure 19. The fibre weight content was slightly higher in the thinner specimens ( $73 \%$ compared to $70 \%$ ), the glass transition temperature was identical.

In fact, results in Figure 19 show a non-Fickian water diffusion modified after a shorter time and $\sqrt{t}_{\mathrm{t}} \mathrm{e}$ in the case of the thin samples. This suggests that the coupling is affected by the scale of the tested samples.

This is an important result, which requires additional study, as it suggests that coupling effects cannot be simply treated in terms of families of stacking sequences but that even for simple tensile loading geometric effects must also be considered.

\section{Conclusions}

The aim of this study is to provide experimental data on how coupling effects between water and mechanical loading affect water uptake and damage development in a carbon/epoxy composite. These effects are shown to be quite small for partially coupled tests, in which water and stress are applied sequentially. However, when they are applied simultaneously large effects are observed (as non-Fickian diffusion), which lead to premature failure. These effects must be understood and modelled if lifetimes are to be predicted. Further work is underway to examine size effects, revealed to be present by preliminary tests, and to examine how cyclic loads affect coupling. Desorption tests should also be performed on stressed samples in order to investigate the reversibility of the water diffusion. 


\section{Bibliography}

[1] R. A. Shenoi, Composite Materials in Maritime Structures: Volume 1, Fundamental Aspects. Cambridge University Press, 1993.

[2] A. P. Mouritz, E. Gellert, P. Burchill, and K. Challis, "Review of advanced composite structures for naval ships and submarines," Compos. Struct., vol. 53, no. 1, pp. 21-42, Jul. 2001.

[3] P. Davies and Y. D. S. Rajapakse, Durability of Composites in a Marine Environment. Springer Science \& Business Media, 2013.

[4] A. C. Loos and G. S. Springer, "Moisture Absorption of Graphite-Epoxy Composites Immersed in Liquids and in Humid Air," J. Compos. Mater., vol. 13, no. 2, pp. 131-147, Apr. 1979.

[5] Y. Diamant, G. Marom, and L. J. Broutman, "The effect of network structure on moisture absorption of epoxy resins," J. Appl. Polym. Sci., vol. 26, no. 9, pp. 3015-3025, Sep. 1981.

[6] T. C. Wong and L. J. Broutman, "Water in epoxy resins Part II. Diffusion mechanism," Polym. Eng. Sci., vol. 25, no. 9, pp. 529-534, Jun. 1985.

[7] J. Zhou and J. P. Lucas, "Hygrothermal effects of epoxy resin. Part I: the nature of water in epoxy," Polymer, vol. 40, no. 20, pp. 5505-5512, Sep. 1999.

[8] S. Popineau, C. Rondeau-Mouro, C. Sulpice-Gaillet, and M. E. R. Shanahan, "Free/bound water absorption in an epoxy adhesive," Polymer, vol. 46, no. 24, pp. 10733-10740, Nov. 2005.

[9] Y. J. Weitsman, "Anomalous fluid sorption in polymeric composites and its relation to fluid-induced damage," Compos. Part Appl. Sci. Manuf., vol. 37, no. 4, pp. 617-623, Apr. 2006.

[10] A. Le Duigou, P. Davies, and C. Baley, "Seawater ageing of flax/poly(lactic acid) biocomposites," Polym. Degrad. Stab., vol. 94, no. 7, pp. 1151-1162, Jul. 2009.

[11] M. D. Placette, X. Fan, J.-H. Zhao, and D. Edwards, "A dual stage model of anomalous moisture diffusion and desorption in epoxy mold compounds," in 2011 12th Intl. Conf. on Thermal, Mechanical Multi-Physics Simulation and Experiments in Microelectronics and Microsystems, 2011, p. 1/8-8/8.

[12] H. R. Dana, A. Perronnet, S. Fréour, P. Casari, and F. Jacquemin, "Identification of moisture diffusion parameters in organic matrix composites," J. Compos. Mater., vol. 47, no. 9, pp. 1081-1092, Apr. 2013.

[13] T. Peret, A. Clement, S. Freour, and F. Jacquemin, "Numerical transient hygro-elastic analyses of reinforced Fickian and non-Fickian polymers," Compos. Struct., vol. 116, pp. 395-403, Sep. 2014.

[14] J. Crank, "The mathematics of diffusion," 1979.

[15] D. Roylance, "Laminated composite plates," Mass. Inst. Technol. Camb., 2000.

[16] M. R. Wisnom, B. Khan, and S. R. Hallett, "Size effects in unnotched tensile strength of unidirectional and quasi-isotropic carbon/epoxy composites," Compos. Struct., vol. 84, no. 1, pp. 21-28, Jun. 2008.

[17] A. E. Mayr, W. D. Cook, and G. H. Edward, "Yielding behaviour in model epoxy thermosets-I. Effect of strain rate and composition," Polymer, vol. 39, no. 16, pp. 3719-3724, 1998.

[18] W. D. Cook, A. E. Mayr, and G. H. Edward, "Yielding behaviour in model epoxy thermosets-II. Temperature dependence," Polymer, vol. 39, no. 16, pp. 3725-3733, 1998. 
[19] A. Gilat, R. K. Goldberg, and G. D. Roberts, "Experimental study of strain-ratedependent behavior of carbon/epoxy composite," Compos. Sci. Technol., vol. 62, no. 1011, pp. 1469-1476, Aug. 2002.

[20] S. Roy, W. Xu, S. Patel, and S. Case, "Modeling of moisture diffusion in the presence of bi-axial damage in polymer matrix composite laminates," Int. J. Solids Struct., vol. 38, no. 42-43, pp. 7627-7641, Oct. 2001.

[21] S. Roy and W. Xu, "Modeling of diffusion in the presence of damage in polymer matrix composites," Int. J. Solids Struct., vol. 38, no. 1, pp. 115-126, Jan. 2001.

[22] C. Suri and D. Perreux, "The effects of mechanical damage in a glass fibre/epoxy composite on the absorption rate," Compos. Eng., vol. 5, no. 4, pp. 415-424, Jan. 1995.

[23] D. Perreux and F. Thiebaud, "Damaged elasto-plastic behaviour of $[+9,-9] \mathrm{n}$ fibrereinforced composite laminates in biaxial loading," Compos. Sci. Technol, vol. 54, no. 3, pp. 275-285, 1995.

[24] D. Perreux and C. Suri, "A study of the coupling between the phenomena of water absorption and damage in glass/epoxy composite pipes," Compos. Sci. Technol., vol. 57, no. 9, pp. 1403-1413, Jan. 1997.

[25] D. Perreux and C. Oytana, "Continuum damage mechanics for microcracked composites," Compos. Eng., vol. 3, no. 2, pp. 115-122, 1993.

[26] J.-E. Lundgren and P. Gudmundson, "A Model for Moisture Absorption in Cross-Ply Composite Laminates with Matrix Cracks," J. Compos. Mater., vol. 32, no. 24, pp. 2226-2253, Dec. 1998.

[27] J.-E. Lundgren and P. Gudmundson, "Moisture absorption in glass-fibre/epoxy laminates with transverse matrix cracks," Compos. Sci. Technol., vol. 59, no. 13, pp. 1983-1991, Oct. 1999.

[28] J. Verdu, Action de L'eau Sur les Plastiques. Ed. Techniques Ingénieur.

[29] Y. J. Weitsman and M. Elahi, "Effects of Fluids on the Deformation, Strength and Durability of Polymeric Composites - An Overview," Mech. Time-Depend. Mater., vol. 4, no. 2, pp. 107-126, Jun. 2000.

[30] Y. J. Weitsman, Fluid Effects in Polymers and Polymeric Composites. Springer Science \& Business Media, 2011.

[31] Y. Weitsman, "Coupled damage and moisture-transport in fiber-reinforced, polymeric composites," Int. J. Solids Struct., vol. 23, no. 7, pp. 1003-1025, 1987.

[32] D. Gueribiz, F. Jacquemin, and S. Fréour, "A moisture diffusion coupled model for composite materials," Eur. J. Mech. - ASolids, vol. 42, pp. 81-89, Nov. 2013.

[33] E. Joseph and D. Perreux, "Fatigue behaviour of glass-fibre/epoxy-matrix filamentwound pipes: Tension loading tests and results," Compos. Sci. Technol., vol. 52, no. 4, pp. 469-480, Jan. 1994.

[34] S. Barré and M. L. Benzeggagh, "On the use of acoustic emission to investigate damage mechanisms in glass-fibre-reinforced polypropylene," Compos. Sci. Technol., vol. 52, no. 3, pp. 369-376, Jan. 1994.

[35] S. Huguet, N. Godin, R. Gaertner, L. Salmon, and D. Villard, "Use of acoustic emission to identify damage modes in glass fibre reinforced polyester," Compos. Sci. Technol., vol. 62, no. 10-11, pp. 1433-1444, Aug. 2002.

[36] P. Wright, X. Fu, I. Sinclair, and S. M. Spearing, "Ultra High Resolution Computed Tomography of Damage in Notched Carbon Fiber-Epoxy Composites," J. Compos. Mater., vol. 42, no. 19, pp. 1993-2002, Oct. 2008.

[37] N. Tual, N. Carrere, P. Davies, T. Bonnemains, and E. Lolive, "Characterization of sea water ageing effects on mechanical properties of carbon/epoxy composites for tidal turbine blades," Compos. Part Appl. Sci. Manuf., vol. 78, pp. 380-389, Nov. 2015. 
[38] Morel E, Bellenger V, Verdu J, Structure-water absorption relationships for amine cured epoxy resins, Polymer, 26, 11, 1985, 1719-24.

[39] Colin X, Verdu J, Humid aging of organic matrix composites, in Durability of Composites in a Marine Environment, Ed. Davies P, Rajapakse DS, Springer 2014, p47114. 

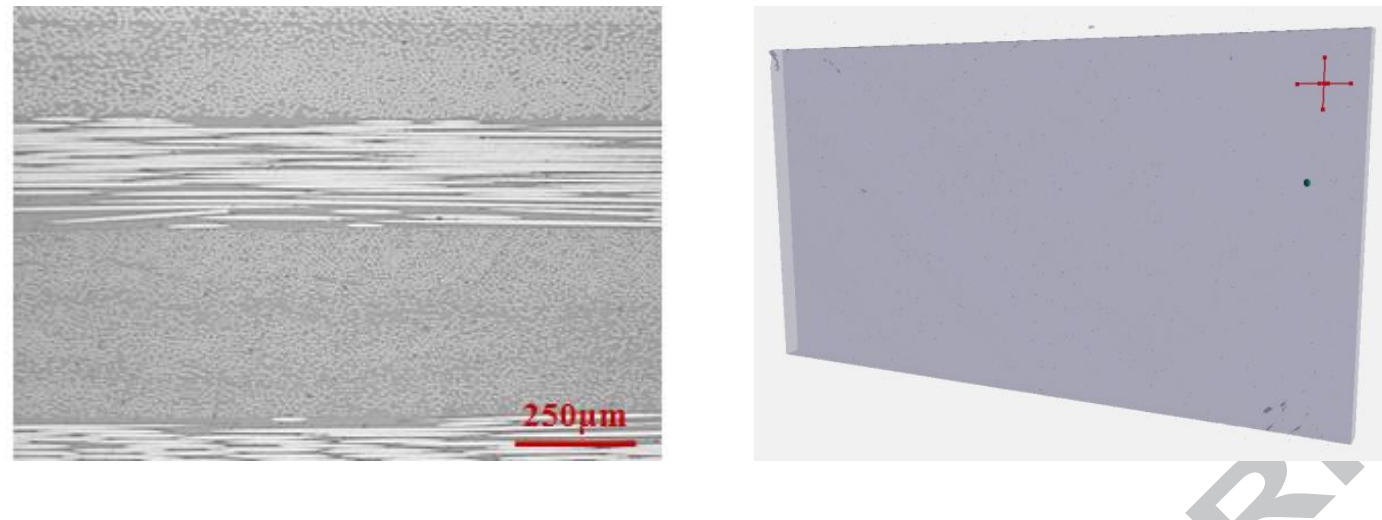

Figure 1. Image of the microstructure of the quasi-isotropic composite, obtained with an optical microscope [left] and with X-Ray tomography (sample of $25 \mathrm{~mm}$ height) [right].

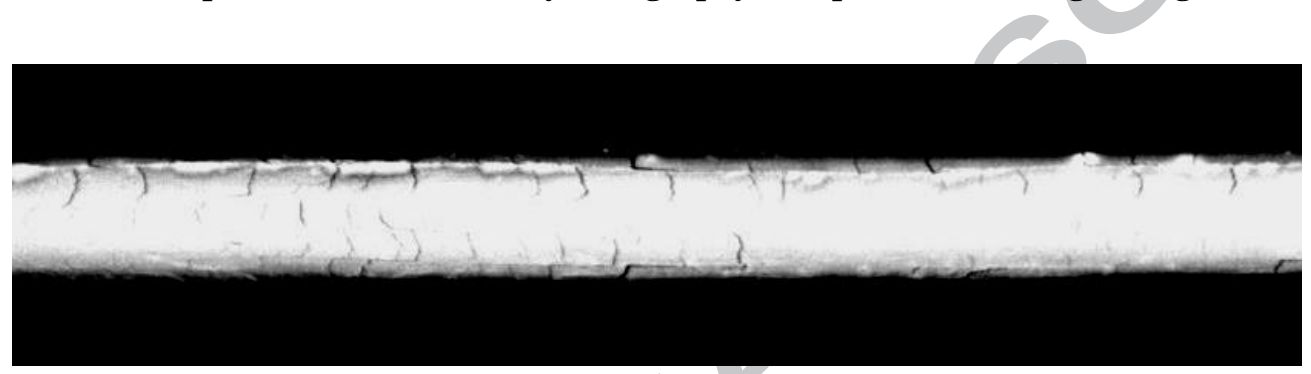

Figure 2. Picture from crack density analysis during tensile test on a $+/-45^{\circ}$ woven composite.
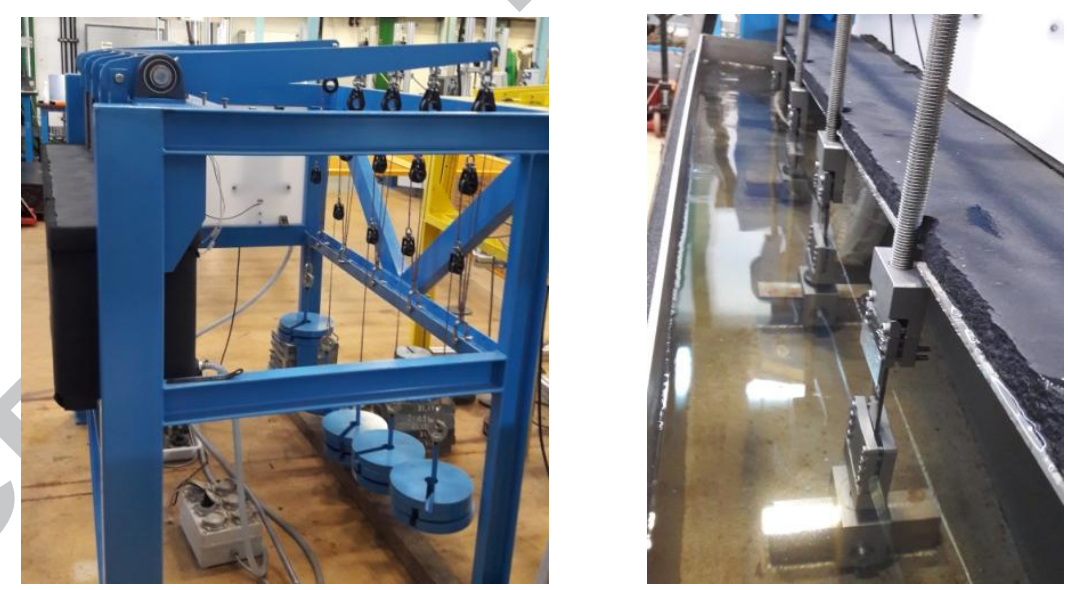

Figure 3. Testing device for coupled tensile stress and water diffusion. 


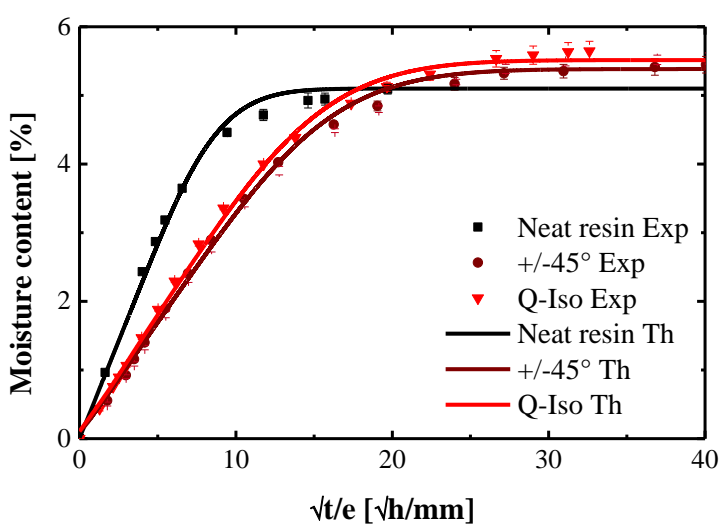

Figure 4. Moisture uptake at $60^{\circ} \mathrm{C}$ in neat resin, $+/-45^{\circ}$ and quasi isotropic composite, experimental data (points) and identification (lines).
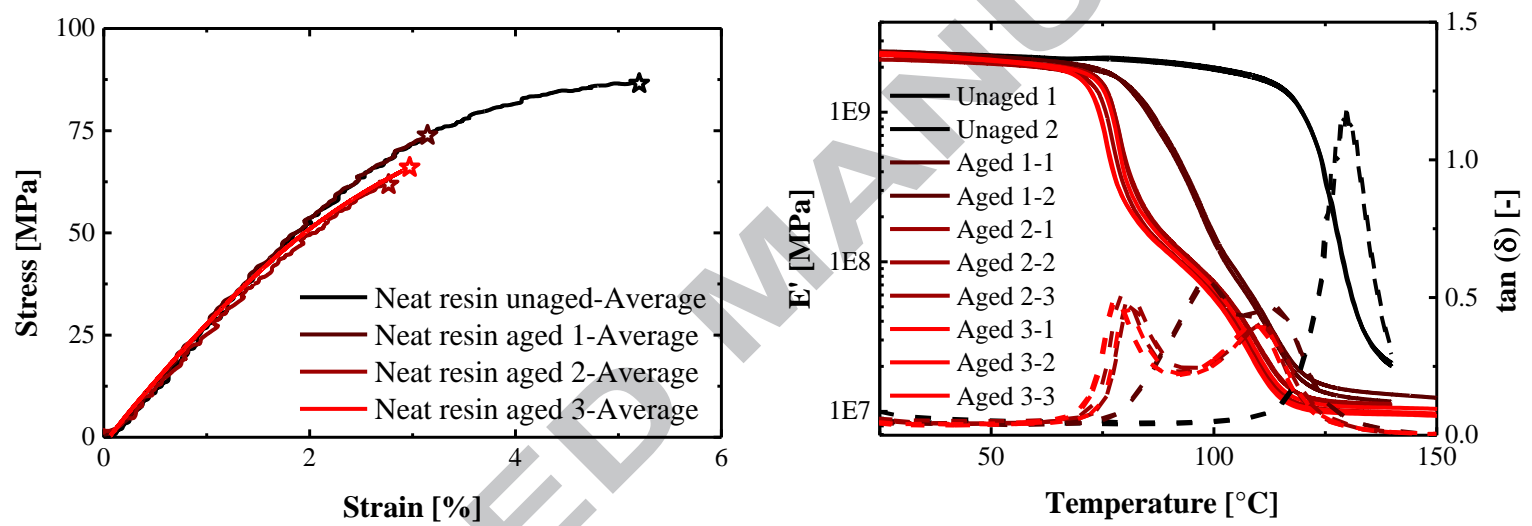

Figure 5. Stress strain curve [left] and storage modulus $E^{\prime}$ and $\tan (\delta)$ vs. temperature [right] for neat resin unaged and at four different stages of ageing.

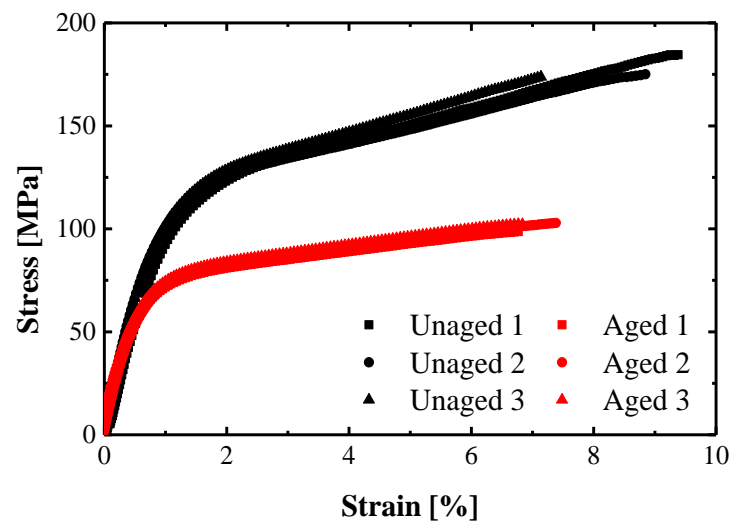

Figure 6. Stress strain curve for tensile test on $+/-45^{\circ}$ woven composite. 

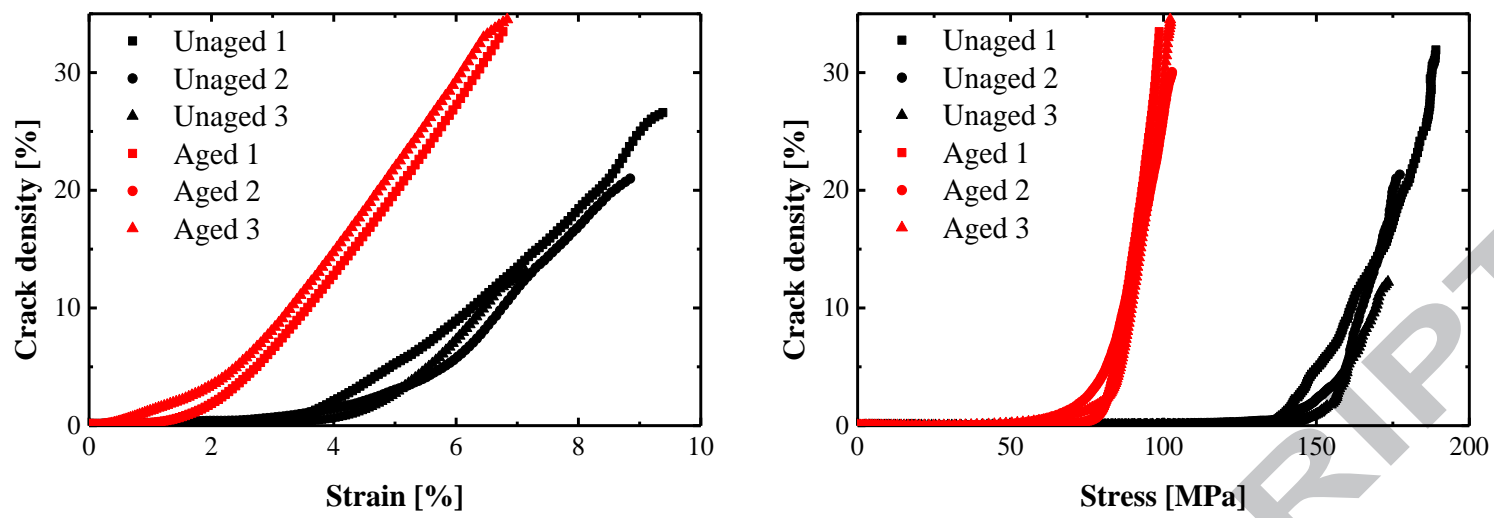

Figure 7. Crack density as a function of strain [left] and stress [right].

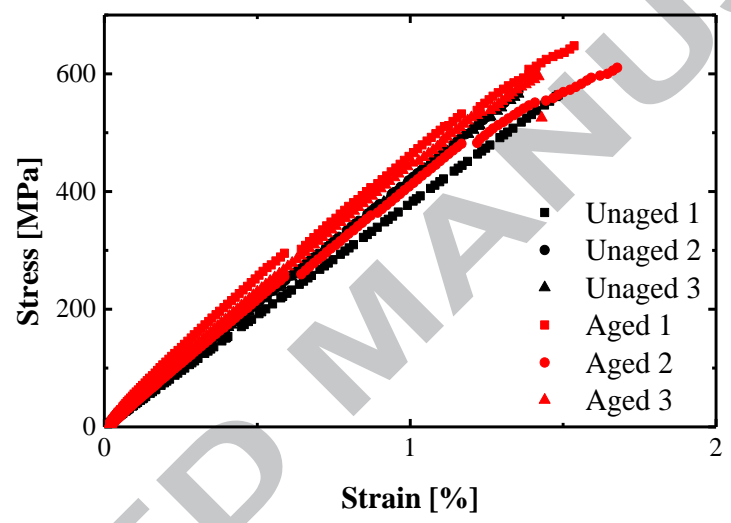

Figure 8. Stress strain curve for tensile test on Q-iso woven composites.
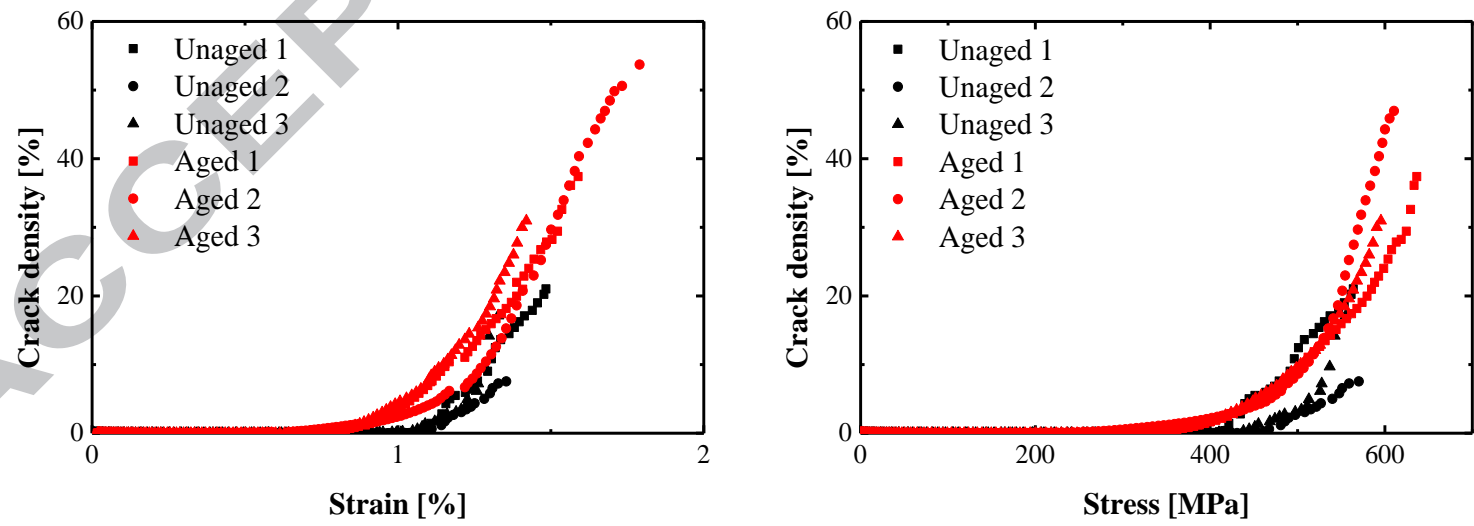

Figure 9. Crack density as a function of strain [left] and stress [right]. 


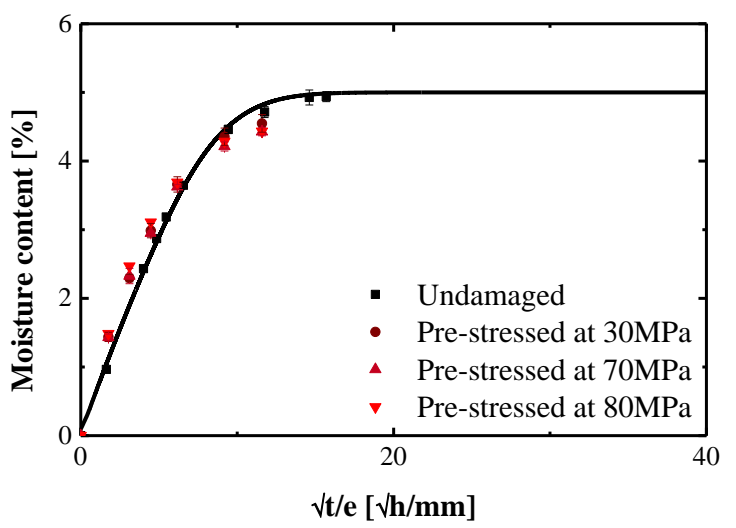

Figure 10. Water uptake in neat resins, pre-stressed to three different loads.

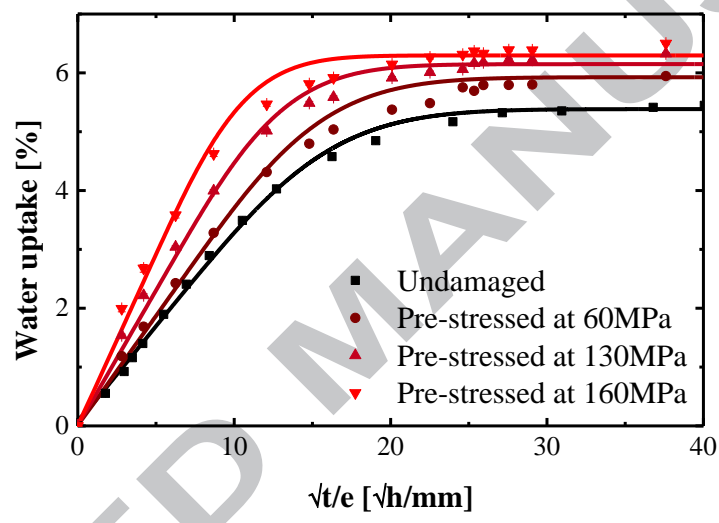

Figure 11. Water uptake in $+/-45^{\circ}$ composites, pre-stressed at three different loads.

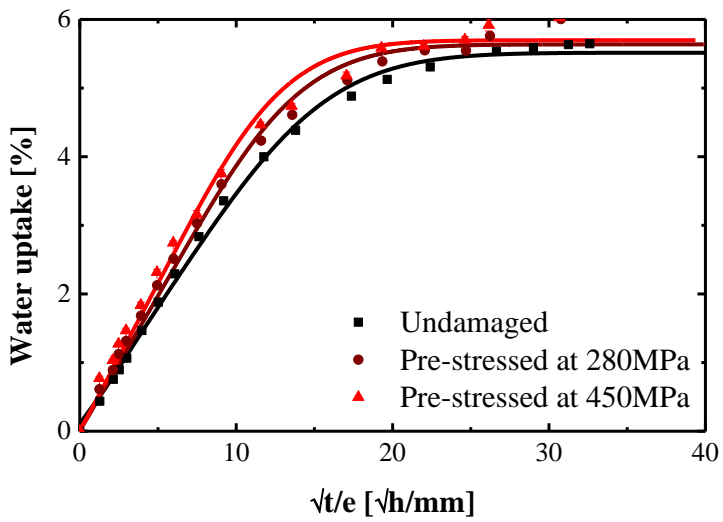

Figure 12. Water uptake in Q-Iso composites, pre-stressed to two different stress levels. 

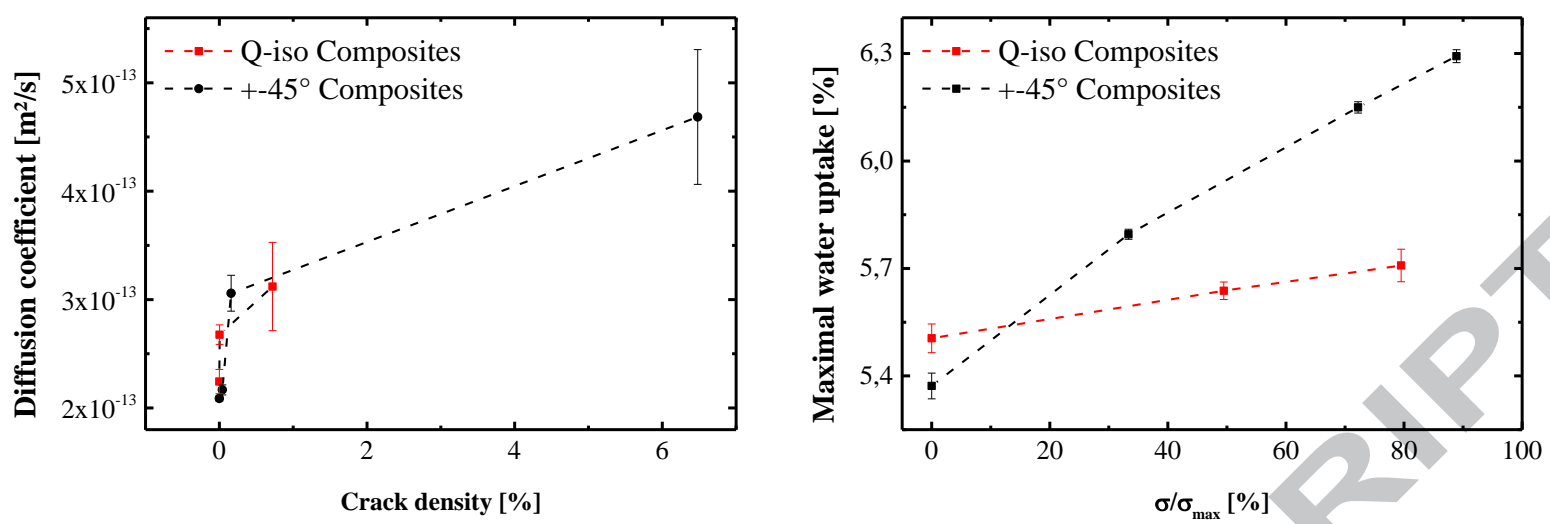

Figure 13. Diffusion coefficients [left] and maximal water uptake [right] in composites after different prestressing levels (with $\sigma_{\max }$, the break stress at $25^{\circ} \mathrm{C}$ and $0 \% \mathrm{RH}$ ).
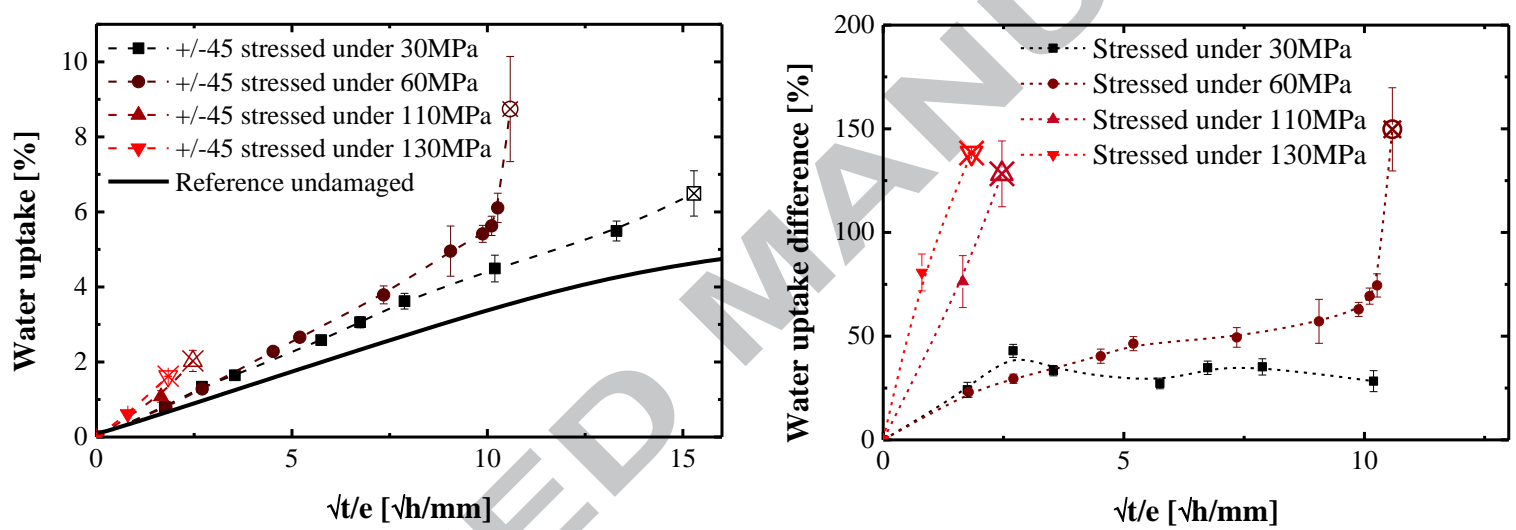

Figure 14. Water uptake $\pm 4^{\circ}$ composites under four different stress levels [left] and the difference with respect to the weight gain of the unstressed reference [right].

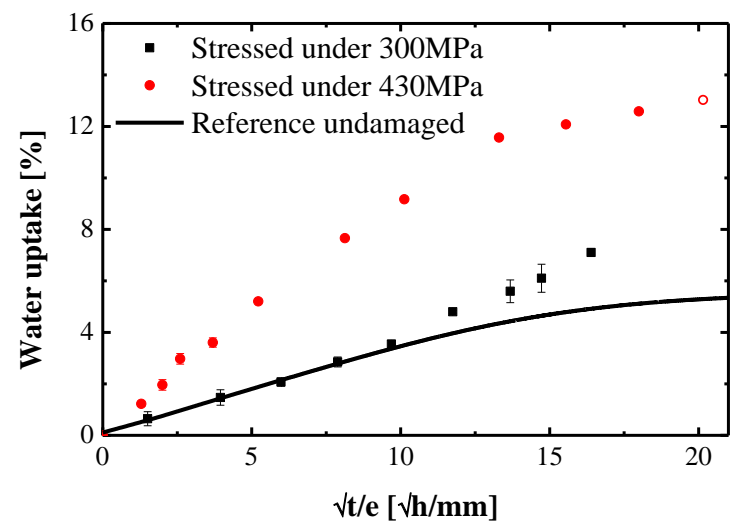

Figure 15. Water uptake in Q-iso composites under two different stress levels. 

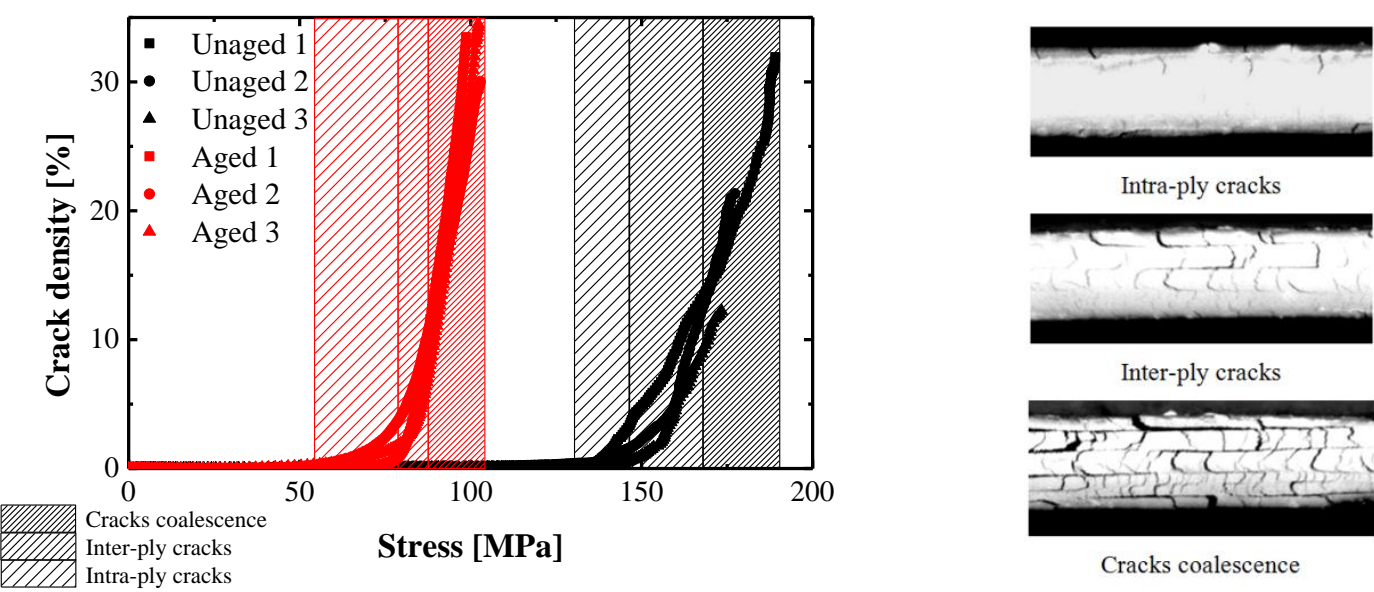

Inter-ply cracks

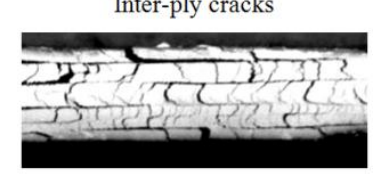

Cracks coalescence

Figure 16. Type of cracks in $+/-45^{\circ}$ composites during tensile tests.
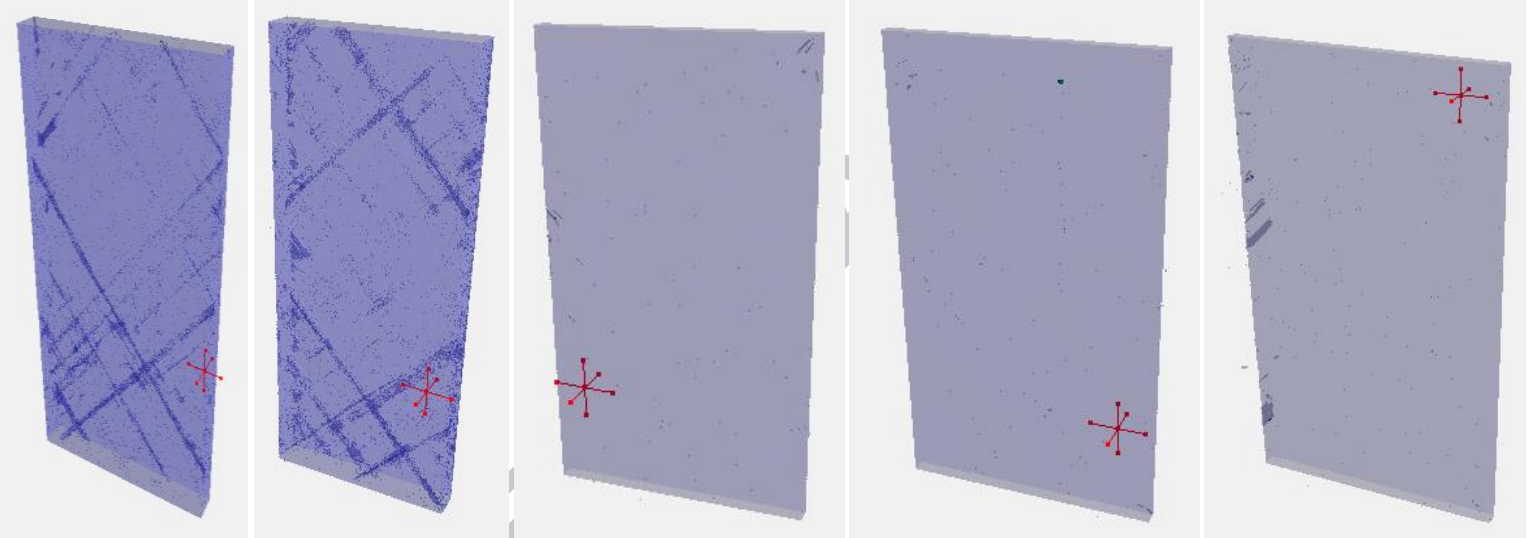

Figure 17. X-Ray tomography images of (from left to right): $\pm 45^{\circ}$ composites pre-stressed at 60 and 130MPa, and quasi-isotropic composites pre-stressed at 0, 280 and 450MPa.
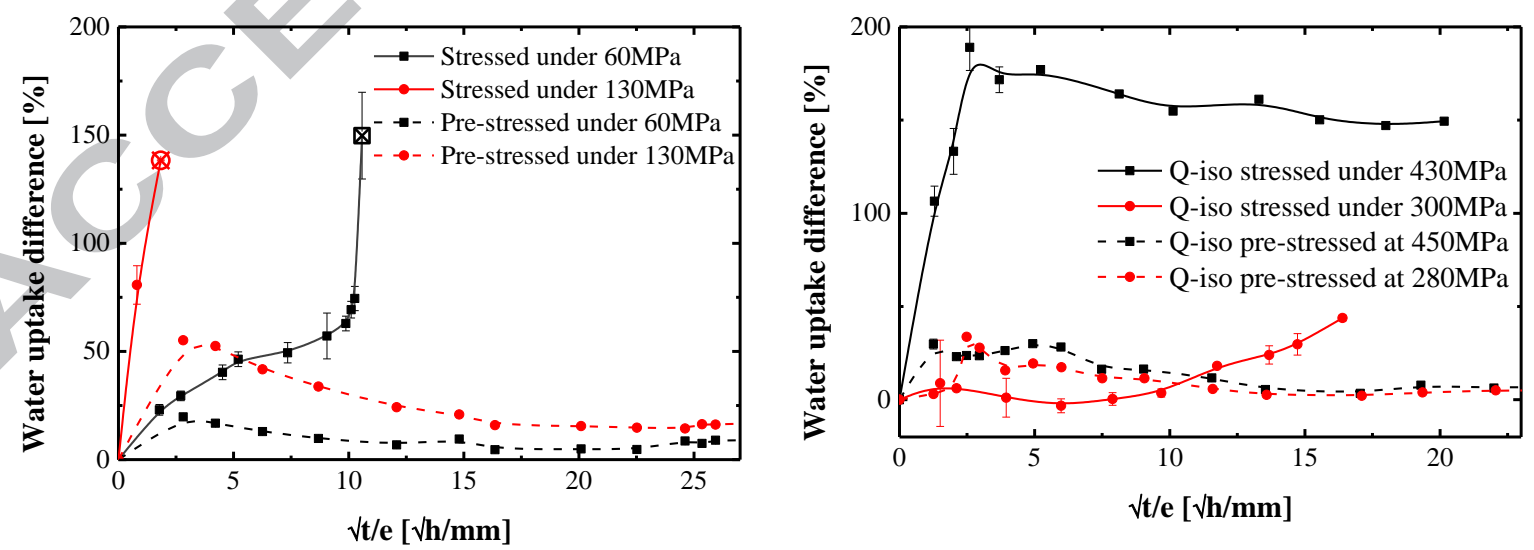

Figure 18. Water uptake difference of stressed/pre-stressed samples with the reference vs. $\sqrt{t}_{t} / \mathrm{e}$ for $\pm 45^{\circ}$ [left] and Q-iso [right] composites. Crossed symbols represent failed samples. 


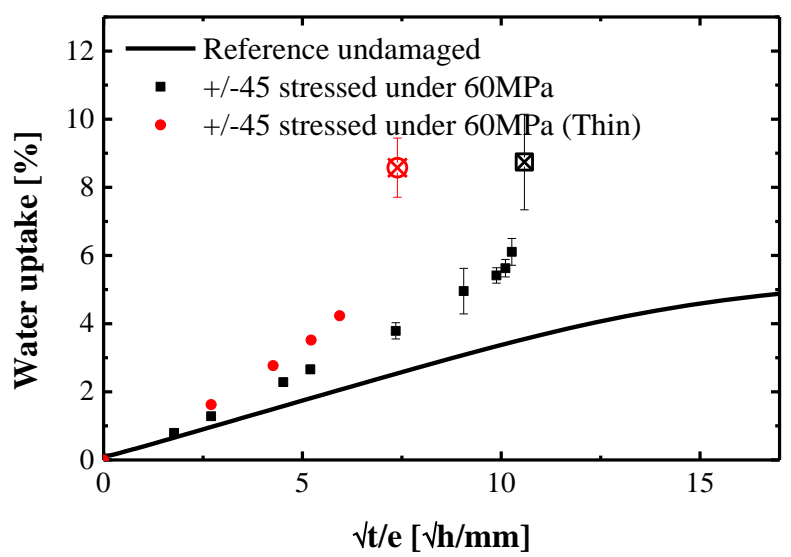

Figure 19. Influence of sample thickness on the water uptake in $+/-45^{\circ}$ composites stressed under $60 \mathrm{MPa}$ in water at $60^{\circ} \mathrm{C}$, standard $(2.2 \mathrm{~mm})$ and Thin $(1 \mathrm{~mm})$. 


\begin{tabular}{cccc}
\cline { 2 - 4 } & $\begin{array}{c}\text { Thickness } \\
{[\mathrm{mm}]}\end{array}$ & $\begin{array}{c}\mathrm{Tg} \\
{\left[{ }^{\circ} \mathrm{C}\right]}\end{array}$ & $\begin{array}{c}\text { Resin content by weight } \\
{[\% \mathrm{~m}]}\end{array}$ \\
\hline Neat resin & $2.6^{ \pm 0.04}$ & $119^{ \pm 1}$ & $30^{ \pm 0.5}$ \\
\hline$+/-45^{\circ}$ composites & $2.2^{ \pm 0.05}$ & $122^{ \pm 0.9}$ & $33^{ \pm 0.7}$ \\
\hline Q-iso composites & $3.2^{ \pm 0.05}$ & $123^{ \pm 0.8}$ & \\
\hline
\end{tabular}

Table 1. Specimens' initial properties (mean values and standard deviations). 


\begin{tabular}{|c|c|c|c|c|c|c|c|c|c|c|c|c|}
\hline & & & \multirow{3}{*}{ 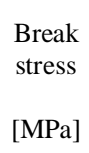 } & \multirow{3}{*}{$\begin{array}{c}\text { Break } \\
\text { strain } \\
{[\%]}\end{array}$} & \multirow{3}{*}{$\begin{array}{c}\text { Modulus } \\
\text { [GPa }]\end{array}$} & \multicolumn{2}{|c|}{ Yield stress } & \multicolumn{2}{|c|}{ Damage threshold } & \multicolumn{2}{|c|}{ Damage speed } & \multirow{3}{*}{$\begin{array}{c}\text { Ultimate crack } \\
\text { density } \\
{[\%]}\end{array}$} \\
\hline & & & & & & Stress & Strain & Stress & Strain & Stress & Strain & \\
\hline & & & & & & {$[\mathrm{MPa}]$} & {$[\%]$} & {$[\mathrm{MPa}]$} & {$[\%]$} & {$[\% / \mathrm{MPa}]$} & {$[\% / \%]$} & \\
\hline \multirow{9}{*}{ 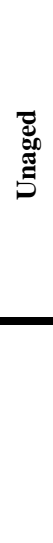 } & \multirow{2}{*}{ Resin } & Average & 81,4 & 4,8 & 2,8 & 75,3 & 3,6 & & & & & \\
\hline & & Standard deviation & 5,3 & 1,4 & 0,0 & 2,2 & 0,2 & & & & & \\
\hline & \multirow{2}{*}{$+/-45$} & Average & 179,7 & 9,0 & 18,5 & 120,3 & 1,5 & 147,7 & 4,3 & 0,75 & 5,5 & 27,4 \\
\hline & & Standard deviation & 8,7 & 1,7 & 6,5 & 2,5 & 0,3 & 6,0 & 0,4 & 0,18 & & 10,8 \\
\hline & \multirow{5}{*}{ Q-iso } & Average & 566,7 & 1,4 & 40,7 & & & 448,3 & 1,4 & 0,13 & 51,3 & 15,2 \\
\hline & & \multirow[t]{4}{*}{ Standard deviation } & 3,2 & 0,1 & 2,3 & & & 28,7 & 0,5 & 0,05 & 21,0 & 6,9 \\
\hline & & & \multirow{2}{*}{$\begin{array}{l}\text { Break } \\
\text { stress }\end{array}$} & \multirow{3}{*}{$\begin{array}{c}\text { Break } \\
\text { strain }\end{array}$} & \multirow{3}{*}{$\begin{array}{c}\text { Modulus } \\
\text { [GPa }]\end{array}$} & \multicolumn{2}{|c|}{ Yield stress } & \multicolumn{2}{|c|}{ Damage threshold } & \multicolumn{2}{|c|}{ Damage speed } & \multirow{3}{*}{$\begin{array}{c}\text { Ultimate crack } \\
\text { density } \\
{[\%]}\end{array}$} \\
\hline & & & & & & Stress & Strain & Stress & & Stress & Strain & \\
\hline & & & {$[\mathrm{MPa}]$} & & & {$[\mathrm{MPa}]$} & {$[\%]$} & [MPa] & {$[\%]$} & [\%/MPa] & {$[\% / \%]$} & \\
\hline \multirow{6}{*}{$\underset{0}{0}$} & \multirow{2}{*}{ Resin } & Average & 61,6 & 2,7 & 2,6 & & & & & & & \\
\hline & & Standard deviation & 3,0 & 0,2 & 0,0 & & & & & & & \\
\hline & \multirow{2}{*}{$+/-45$} & Average & 101,2 & 7,0 & 12,4 & 74,1 & & 77,1 & 1,4 & 1,74 & 6,4 & 32,7 \\
\hline & & Standard deviation & 2,3 & 0,3 & 0,5 & 0,9 & 0,1 & 4,4 & 0,5 & 0,38 & 1,4 & 2,3 \\
\hline & \multirow{2}{*}{ Q-iso } & Average & 617,8 & 1,6 & 46,4 & & & 416,7 & 1,0 & 0,28 & 78,8 & 41,3 \\
\hline & & Standard deviation & 26,8 & 0,1 & 1,7 & & & 2,9 & 0,0 & 0,12 & 14,8 & 12,7 \\
\hline
\end{tabular}

Table 2. Mechanical properties of unaged and aged materials. 


\begin{tabular}{cccc}
\cline { 3 - 4 } & & $\begin{array}{c}\text { Stress limit } \\
\text { Unaged } \\
{[\mathrm{MPa}]}\end{array}$ & $\begin{array}{c}\text { Stress limit } \\
\text { Aged } \\
{[\mathrm{MPa}]}\end{array}$ \\
\hline \multirow{2}{*}{ Intra-ply cracks } & Average & 128,0 & 61,0 \\
& Standard deviation & 9,6 & 9,6 \\
\hline \multirow{2}{*}{ Inter-ply cracks } & Average & 148,5 & 82,5 \\
& Standard deviation & 6,9 & 1,1 \\
\hline \multirow{2}{*}{ Cracks coalescence } & Average & 172,5 & 87,7 \\
& Standard deviation & 9,6 & 3,7 \\
\hline
\end{tabular}

Table 3. Stress levels corresponding to damage stages in a $+/-45^{\circ}$ composite under tensile stress. 